\title{
A standard drink? There's no such thing
}

$\mathrm{W}$ hen it comes to drinking alcohol, how much is too much? It depends on where you live. Some countries recommend less than half of what Canadian pundits say is okay. Then again, Americans' limits are higher than ours.

The authors of a new study in Addiction had a simple task in mind when they set out to examine the world's safe drinking guidelines: they wanted to generate a single-page reference to help alcohol researchers. So Keith Humphreys and Dr. Agnieszka Kalinowski looked at recommendations issued by countries that offered them - 37 in all — and compared.

"It turned out to be more interesting than we thought," says Humphreys. Guidelines on safe drinking differ surprisingly, and often dramatically, countryto-country, he says.

In fact, there was little agreement on anything.

Australian, Swedish and Indian men, among others, were told to keep consumption below 20 grams of pure ethanol per day, but Polish, Vietnamese and Japanese men were allowed double that. (Canadian men were permitted a splash more: 40.7 grams.) Chilean and American men could toss back 56 grams. And while a few countries had identical cutoffs for men and women, most, including Canada, recommended women drink less. But there was no consensus on how much less.

Weekly recommended restrictions also varied, from a low of 100 grams in China, to a high of 280 grams in Vietnam and Poland. Calculations indicate that the French were expected to imbibe daily and cap themselves identically on each of those days, but in other places, like the United States, drinking your daily limit every day would put you well over the weekly maximum. Some countries recommend occasional abstinence; others set limits higher for so-called special occasions.

"Some of this is not scientific, it's

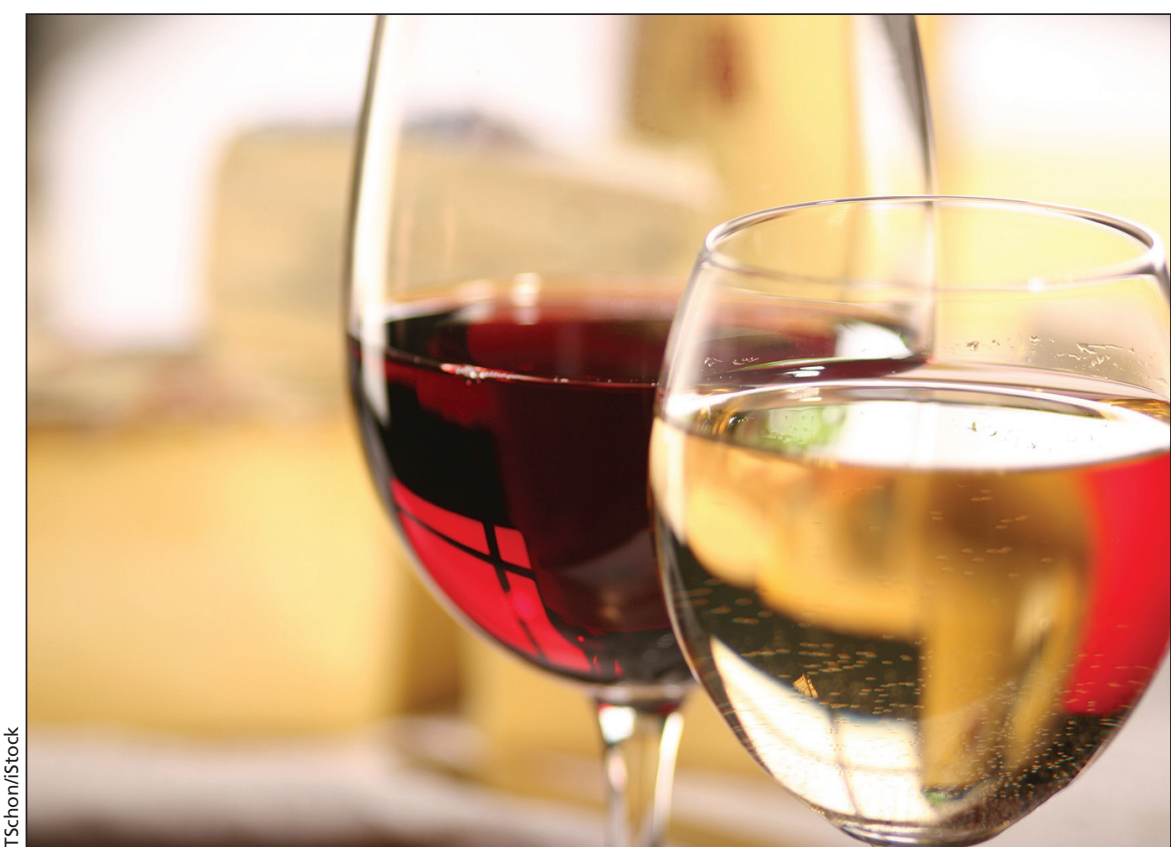

The alcohol limit for Canadian men is $\mathbf{4 0 . 7}$ grams of pure ethanol per day; Swedes are limited to 20.

cultural," says Humphreys. "There are different drinking styles."

The researchers found that even the definition of a "standard drink" varied. On the low end were the United Kingdom and Iceland, where a standard drink contained 8 grams of ethanol; Austria was on the high end, where 20 grams was deemed standard. Canada placed near the middle, with a standard drink containing approximately 13.6 grams. The World Health Organization pegs the standard at 10 grams.

The researchers found that the definition of a standard drink varied by $250 \%$ worldwide. This discrepancy has important implications for crossborder medical research, they say. When research in one country finds benefits of "moderate" drinking, for instance, it's important to be sure ideas of moderation are the same in other jurisdictions.

Jurgen Rehm, an epidemiologist at the Centre for Addiction and Mental Health in Toronto, agrees. He says it's important to convert consumption into grams of pure ethanol, never to rely on standardized questionnaires that use "drink" as a measure, and to understand local drinking customs. He points out that researchers in other nutritional fields face similar problems. "What is one order of fries?" he asks, pointing out that Belgian and US McDonald's customers may have very different ideas. "If you just use portions you get nowhere."

But the measurement of alcohol makes it difficult for drinkers to know if they are complying with guidelines. After all, alcohol is not measured by the gram at pubs or in liquor stores. Canadian labels on cans, bottles and boxes typically show only percent alcohol and total milliliters of content. Bars sell booze in shots, pints, glasses and other nebulous sizes. Muddying the water further are terms like "proof" and "unit."

"We expect these people to do mental calculations to figure out what the heck they are drinking," says Rehm. His research indicates that people "fail spectacularly" when asked to guess by taste or tipsiness. 
Rehm believes that alcohol should be clearly labelled, the way milk is. On dairy products a consumer sees what fraction of his daily calcium intake he is consuming; on alcohol products he should see what proportion of his daily recommended alcohol limit he is taking in. Humphreys and Kalinowski acknowledge in their paper, however, that there is no evi- dence that understanding guidelines will induce people to act on them.

In January 2016, the UK department of health proposed new drinking limits, and acknowledged that even small quantities of alcohol increase the risk of various cancers, including breast, bowel and esophageal. Cancer research indicates that alcohol is a cumulative carcinogen, that there is no known safe limit and every drink raises the risk of cancer. Cardiovascular research, on the other hand, indicates that moderate drinking offers some protection.

Real safe alcohol levels may remain elusive, Humphreys admits: "It may not be something that we'll ever actually know." - Alison Motluk, Toronto, Ont.

CMAJ 2016. DOI:10.1503/cmaj.109-5273 